\title{
Determination of caffeic acid in root and rhizome of Black cohosh (Cimicifuga racemosa (L.) Nutt.)
}

\author{
Karolina Zapala ${ }^{1}$, Grazyna SzymczaK ${ }^{2}$, Magdalena WojciaK-Kosior ${ }^{1 \star}$
}

${ }^{1}$ Department of Analytical Chemistry, Medical University of Lublin, Chodzki 4a, 20-093, Lublin, Poland

${ }^{2}$ Botanical Garden of Maria Curie-Skłodowska University in Lublin, Slawinkowska 3, 20-810 Lublin, Poland

\begin{tabular}{l}
\hline ARTICLE INFO \\
\hline Received 07 July 2014 \\
Accepted 17 July 2014 \\
\hline
\end{tabular}

\section{KEYWORDS:}

caffeic acid,

Cimicifuga racemosa,

phenolic acids.

\begin{abstract}
Cimicifuga racemosa, is a plant with a diverse and long history of medicinal use. Caffeic acid, bioactive compound, which often occurs with other polyphenols can influence the biological activity of this plant. The aim of our work was quantitative analysis of caffeic acid in roots and rhizomes of two varieties of C. racemosa. Analysis was performed by HPLC method. The extracts were separated on C18 reversed-phase column using mixture of methanol, water and formic acid $(25: 75: 0.5 \mathrm{v} / \mathrm{v} / \mathrm{v})$ as a mobile phase. The flow rate of eluent was $1.0 \mathrm{ml} \cdot \mathrm{min}^{-1}$. The obtained validation parameters such as linearity, linear regression equation and precision expressed as a relative standard deviation were adequate for quantitative determination. Caffeic acid was found in all tested extracts. The highest total amount of caffeic acid was determined in C. racemosa var. racemosa $\left(255.3 \mu \mathrm{g} \cdot \mathrm{g}^{-1}\right)$ while its concentration in C. racemosa var. cordifolia was significantly lower $\left(213.0 \mu \mathrm{g} \cdot \mathrm{g}^{-1}\right)$.
\end{abstract}

\section{INTRODUCTION}

Phenolic compounds are secondary metabolites naturally present in nearly all plant materials, mostly in fruits, vegetables, grains and in food products of plant origin such as tea, wine or coffee [2]. Caffeic acid (3,4-dihydroxycinnamic acid) (Fig. 1) belonging to hydroxycinnamic acid derivatives is one of the most known plant polyphenol. This compound has a broad spectrum of pharmacological activities including anti-inflammatory, antibacterial, anti-tumor, antiviral and immunomodulatory effects $[5,10,12,13]$. Its antioxidant and neuroprotective properties have also been proven. Pharmacological studies have shown that caffeic acid protects the brain against oxidative brain damage induced by hydrogen peroxide $[1,6]$ and might protect against cardiovascular diseases [8].<smiles>O=C(O)/C=C/c1ccc(O)c(O)c1</smiles>

Figure 1. Caffeic acid

Cimicifuga racemosa (L.) Nutt. (Actaea racemosa, also known as black cohosh), is a perennial herb belonging to the buttercup family (Ranunculaceae) [3]. The roots and rhizomes of $C$. racemosa are traditionally used to treat a variety of disorders, e.g. abnormalities in kidney function, malaria, rheumatism, general malaise, sore throat, menstrual irregularities and for the relief of menopause-related symptoms $[4,7]$. Clinical studies suggest that black cohosh is effective in relieving emotional symptoms, especially depression or anxiety, and hot flushes during menopause [3]. The chemical constituents of $C$. racemosa include two classes of secondary metabolites: triterpene glycosides and phenolics compounds [4]. Triterpenes (fraction specified name cimicifugin) and isoflavones are mainly responsible for estrogenic activity. However, phenolic compounds, e.g. phenolic acids can also influence on biological activity of black cohosh.

The aim of our work was quantitative analysis of caffeic acid in roots and rhizomes of black cohosh and comparison of its content in two varieties: C. racemosa (L.) Nutt. var. racemosa and C. racemosa (L.) Nutt. var. cordifolia (Pursh) Gray.

\section{MATERIALS AND METHODS}

Chemicals and reagents. HPLC-grade methanol was purchased from Merck (Darmstadt, Germany). Water for chromatography was deionized and purified by ULTRAPURE Milipore Direct-Q ${ }^{\circledR}$ 3UV-R (Merck, Darmstadt, Germany). Caffeic acid standard was from Sigma (St. Louis, MO, USA).

Standard and sample preparation. Caffeic acid standard was accurately weighted $(1.25 \mathrm{mg})$ and dissolved in $25 \mathrm{~mL}$ 
of methanol (final concentration was $50 \mu \mathrm{g} \cdot \mathrm{mL}^{-1}$ ). Standard solutions were prepared by dilution of stock solution in methanol to appropriate concentrations.

Rhizomes and roots of C. racemosa var. racemosa and C. racemosa var. cordifolia were collected in Botanical Garden of Maria Skłodowska-Curie University (UMCS) of Lublin (September 2013) and next, dried and pulverized. $1 \mathrm{~g}$ of each plant material was weighed for the research. Samples were extracted with $20 \mathrm{~mL}$ of methanol in ultrasonic bath $(3 \times 15 \mathrm{~min})$. The combined extracts were concentrated to $10 \mathrm{~mL}$.

Chromatography. Chromatographic determination was performed on VWR Hitachi Chromaster 600 chromatograph (Merck, Darmstadt, Germany) with pump (5160), a degasser, thermostat (5310), autosampler (5260), DAD detector (5430) and EZChrom Elite software.

The extracts were analyzed on $\mathrm{C} 18$ reversed-phase column $(25 \mathrm{~cm} \times 4.0 \mathrm{~mm}$ i.d., $5 \mu \mathrm{m}$ particle size $)$, LiChrospher 100 (Merck), at temperature of $25^{\circ} \mathrm{C}$. Twenty $\mu \mathrm{L}$ of each sample was injected. Mixture of methanol, water and formic acid $(25: 75: 0.5 \mathrm{v} / \mathrm{v} / \mathrm{v})$ was used as a mobile phase. The flow rate of eluent was $1.0 \mathrm{ml} \cdot \mathrm{min}^{-1}$. The data were collected in the range of wavelength from 200 to $400 \mathrm{~nm}$.

\section{RESULTS AND DISCUSSION}

Many factors can affect the amount of biologically active compounds in plants, e.g. composition of soil, environmental conditions, as well as a time of harvest. In our research, the content of caffeic acid in two varieties of C. racemosa harvesting in the same period and growing under the same conditions was determined.

The extraction conditions for isolation of caffeic acid and chromatographic conditions of separation of extracts from roots and rhizomes of C. racemosa were established on the basis of literature [9]. Phenolic acids are polar group of plant metabolites, thus the mobile phases containing methanol or acetonitrile with high amount of water, from 75 to $85 \%$ are recommended for their analysis $[11,14]$. In our experiments, eluent consisting of methanol and $75 \%$ of water enabled the appropriate separation of investigated compound from the other components of extract (Fig. 2). The small addition of formic acid was necessary to improve the shape of chromatographic peaks. Caffeic acid was identified by comparison of retention time $\left(t_{R}=11.13 \pm 0.06 \mathrm{~min}\right)$ and obtained UV spectrum with standard (Fig. 3).

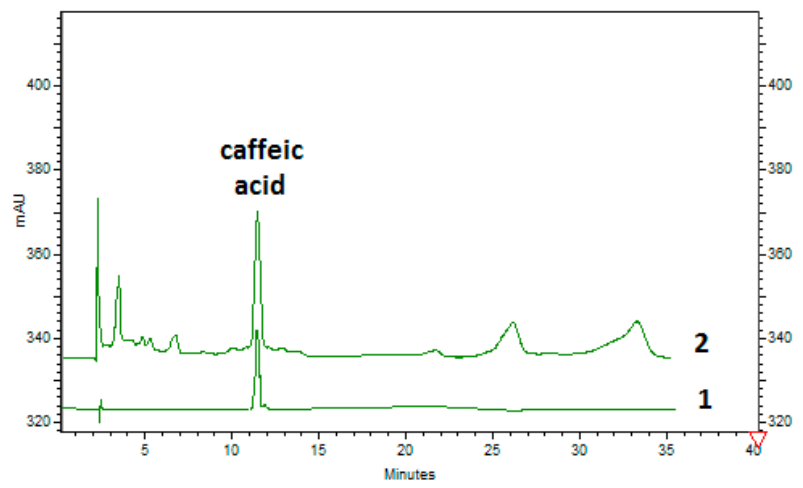

Figure 2. Chromatogram: 1 - standard of caffeic acid, 2 - Cimicifuga racemosa var. cordifolia rhizome extract

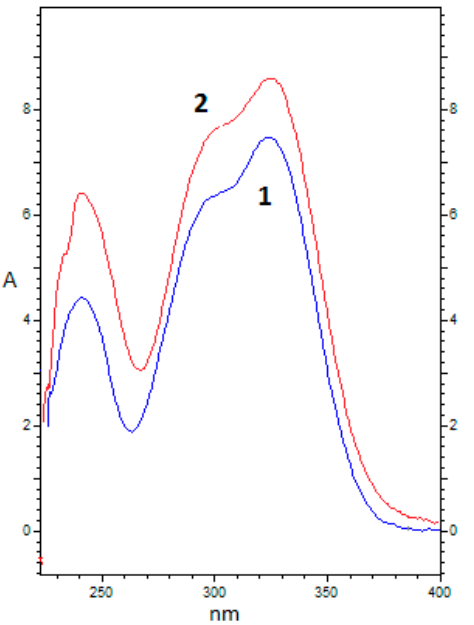

Figure 3. Spectrum: 1 - standard of caffeic acid, 2 - caffeic acid from Cimicifuga racemosa extract

The quantitative analysis was performed at $\lambda=320 \mathrm{~nm}$. The amounts of caffeic acid in extract samples were calculated from the calibration plot. Five standard solutions in concentrations: $5.0,12.5,25,37.5$ and $50 \mu \mathrm{g} \cdot \mu \mathrm{L}^{-1}$ were used for the construction of calibration curve $(n=3)$. The quantification was conducted on the basis of linear regression least square model. The obtained parameters such as linearity $(\mathrm{r}=$ $0.9998)$, linear regression equation $(y=412357 x-674814)$ and precision expressed as a relative standard deviation (RSD range: $0.54-1.66 \%$ ) were sufficient for quantitative determination.

Investigated compound was found in all tested extracts. However, it can be seen that the amount of caffeic acid strongly depends on the variety of plant. Only slight difference of CA content was noted in rhizomes of both varieties, the amount of CA was only about $3.5 \%$ higher in var. cordifolia. However, its concentration determined in root of var. cordifolia was significantly lower (approximately $41.8 \%$ ). As our experiments showed, both of the varieties had tendency to accumulate CA in rhizomes. Moreover, the var. racemosa produced the higher total amount of caffeic acid. The results of quantification are presented in Table 1.

Table 1. The results of caffeic acid quantification in Cimicifuga racemosa extrats

\begin{tabular}{|l|c|c|c|}
\hline \multirow{2}{*}{ Plant material } & \multicolumn{3}{|c|}{$\begin{array}{c}\text { Caffeic acid content } \\
\left(\mu \mathrm{g} \cdot \mathrm{g}^{-1} \text { of dry plant material }\right)\end{array}$} \\
\cline { 2 - 4 } & rhizome $\pm \mathrm{SD}$ & root $\pm \mathrm{SD}$ & total amount \\
\hline C. racemosa var. racemosa & $141.7 \pm 2.1$ & $113.6 \pm 2.4$ & 255.3 \\
\hline C. racemosa var. cordifolia & $146.9 \pm 0.4$ & $66.1 \pm 1.2$ & 213.0 \\
\hline
\end{tabular}

\section{SUMMARY}

The caffeic acid content was investigated in roots and rhizomes of two varieties of $C$. racemosa. The chromatographic system consisting of methanol, water and formic acid $(25: 75: 0.5 \mathrm{v} / \mathrm{v} / \mathrm{v})$ provided its appropriate separation from the other components in analysed samples. The highest total amount of caffeic acid was determined in C. racemosa var. racemosa $\left(255.3 \mu \mathrm{g} \cdot \mathrm{g}^{-1}\right)$ while its concentration in C. racemosa var. cordifolia was significantly lower $\left(213.0 \mu \mathrm{g} \cdot \mathrm{g}^{-1}\right)$. This compound can influence the biological activity of investigated plant extracts. 


\section{REFERENCES}

1. Anwar J. et al.: Effects of caffeic acid on behavioral parameters and on the activity of acetylcholinesterase in different tissues from adult rats. Pharmacol. Biochem. Behav., 103, 386, 2012.

2. Gülçin Ï.: Antioxidant activity of caffeic acid (3,4-dihydroxycinnamic acid). Toxicology 217, 213, 2006.

3. Hui Z. et al.: Effects of black cohosh and estrogen on the hypothalamic nuclei of ovariectomized rats at different temperatures. J. Ethnopharmacol. 142, 769, 2012.

4. Jiang B. et al.: The value of plant collections in ethnopharmacology: a case study of an 85-year-old black cohosh (Actaea racemosa L.) sample. J. Ethnopharmacol. 96, 521, 2005.

5. Khan A.Q. et al.: Caffeic acid attenuates 12-O-tetradecanoyl-phorbol13 -acetate (TPA)-induced NF- $\kappa \mathrm{B}$ and COX-2 expression in mouse skin: abrogation of oxidativestress, inflammatory responses and proinflammatory cytokine production. Food Chem. Toxicol. 50, 175, 2012.

6. Leite F. R. F., Santos W. de J. R., Kubota L. T.: Selective determination of caffeic acid in wines with electrochemical sensor based on molecularly imprinted siloxanes. Sensors and Actuators B: Chemical $193,238,2014$
7. Low Dog T., Powell K.L., Weisman S.M.: Critical evaluation of the safety of Cimicifuga racemosa in menopause symptom relief. Menopause 10, 299, 2003.

8. Margaret R.: Alternative treatments for the menopause. Clin. Obstet. Gynecol. 23, 151, 2009.

9. Naczk M., Shahidi F.: Exctraction and analysis of phenolics in food. J. Chromatogr. A 1054, 95, 2004.

10. Oh J. et al.: Antioxidant and antimicrobial activities of various leafy herbal teas. Food Control 31, 403, 2013.

11. Tomás-Barberán F.A. et al.: HPLC - DAD - ESIMS analysis of phenolic compounds in nectarines, peaches, and plums. J. Agric. and Food Chem. 49, 4748, 2001.

12. Weng C., Yen G.: Chemopreventive effects of dietary phytochemicals against cancer invasion and metastasis: phenolic acids, monophenol, polyphenol, and their derivatives. Cancer Treat. Rev. 38, 76, 2012.

13. Xie Y. et al.: Caffeic acid derivatives: A new type of influenza neuraminidase inhibitors. Bioorg. Med. Chem. 23, 3556, 2013. 